\title{
Kindergarten Study-Unit: Development and Nurturing Awareness of the Existence of the Arab 'other' and the Existence of the Jewish 'other' by Means of the Arts at the Preschool Level
}

\author{
By Luda Kriger
}

\begin{abstract}
In this paper, we describe an educational initiative which is a studyunit for kindergarten: "Development and nurturing awareness of the existence of the Arab 'other' and the existence of the Jewish 'other' by means of the arts at the preschool level". The unit was written as part of my graduate studies for the $M$. Ed. degree at the Oranim College under the guidance of Prof. Moshe Itzhaki. It evolved from my need to affect change in matters that I am responsible for in the educational field where I work. In Israeli society, the Jewish-Arab conflict is prominent (Bar-Tal, 2007). There is discernible cultural withdrawal between Jewish society and Arab society, while the two separate education systems deepen the alienation between them from very early childhood. The lack of curricula about the "other" leaves the students in a void of ethnocentric ignorance that is filled by other entities which are supportive of the development of the conflict ethos (Yona, 2007). The proposed study unit exposes the children to the narrative of another cultural group that exists in the social reality in which they are raised. This is achieved using the arts and through intercultural meetings between Jewish children and Arab children. This initiative is implemented in my kindergarten since three years, thanks to a grant received from the Fund for Innovative Teaching and thanks to an Encouragement Award from the Oranim College. As part of the initiative children from various sectors meet together and interact in Hebrew and Arabic, learning about a different culture. This process leads to experiential and meaningful learning that has received support in both the Jewish and Arab communities.
\end{abstract}

\section{Introduction}

In the multiple identities that make up Israeli society there are various types of "other". In this reality it is important to become familiar with the "different". Familiarity with it reduces the level of fear of it on the personal

*Director, Amalia Lavi Kindergarten Yoqne`Am, Israel. 
and collective plane, a fear that often stems mainly from lack of knowledge of the other (Gover, 2000; Nadler, 2000). Oron (1996) sees the Arab "Other" as the ultimate "Other" in Israeli society. The high level of cultural introversion deepens the Jewish-Arab chasm while also increasing the mutual separation between the two societies. The two separate educational systems, starting at kindergarten age, maintain the cultural separation between them (Elhaj, 2003; Yona, 2007). Totri (2009) claims that "a Jewish child can grow to 18 years old without even once meeting an Israeli-Arab, not in real life and not on TV" (ibid: 1). Hardly any curricula exist for early childhood that focus on knowing the Arab "other". Few school projects exist that deal with getting to know the "other" (Bar-Shalom, 2004). This phenomenon is not common in kindergartens in Israel. Studies show that conceptions and stereotypes that exist in society about the "other" can already be found in early childhood (Teichman, 2006). Therefore, we have to start education for multiculturalism at the earliest age possible.

From this arose my need to create a study-unit for kindergarten, in order to create a multi-cultural educational environment within the kindergarten and expose the children to the "other" through the arts and inter-cultural meetings between children of Jewish and Arab kindergartens.

In chapter 2 I will first review the expressions of the Jewish-Arab conflict and examine the means of constructing a national narrative. Later I'll examine society's attitude to the "other" and highlight the importance to Israel of education for multiculturalism. Finally, I will discuss the place of arts in early childhood education. In chapter 3 I will describe the process of implementation of this educational initiative and demonstrate the main activities that were held as part of it.

\section{Literature Review}

This initiative deals with becoming familiar with the Arab "other" and the Jewish "other" in early childhood. In order to understand the importance of this issue, its complexity and the sensitivities involved, we have to examine the roots of the Jewish-Arab conflict.

\section{Expressions of the Ethos of the Jewish-Arab Conflict in Israeli Society}

The ongoing Jewish-Arab conflict is ever-present on the public agenda. It is founded on historical political problems and has a social-psychological texture in accompaniment. As a society's goals are set they are presented as essential to its existence and form the basis of the conflict between various societies. These goals form a motivating source in the struggle for their achievement, while society is willing to carry the heavy toll the struggle entails. The goals of the conflict are seen to be justified and they negate the legitimacy of the opposing group's goals, leading to non-normative reactions by members of society. In the Israeli-Arab conflict this is expressed in the goals related to territorial demands, to the borders of the state and to the 
ideologies of the two national movements - each of whom claims Israel to be its homeland. Another expression of the conflict's culture is the delegitimization of the opposing group which creates negative stereotyping and de-humanization of the enemy (Orin, 1996; Bar-Tal, 2006, Bar-Tal, 2007). Members of societies in conflict often see themselves as victims. This point of view encourages the nation's motivation and its ambition to achieve its national goals. Therefore, these societies invest in nurturing their social beliefs, related to their self perception as victims. The Israeli people's self perception as victims is linked to the religious perception that developed a siege mentality throughout the people's history (Bar-Tal, 2007; Nadler, 2000). Also, the description of the struggle between weak Jews and strong Arab countries enshrines the myth of "the war of the few against the many" which is rooted in Jewish history (Sela, 2007) and is one of the proto-generic concepts in the construction of the nation (White, 1974). The choice of collective self perception as a victim affects the process of building the national narratives of the studied societies, which we will examine in the next section.

\section{The Process of Constructing a Nation's Historical Narrative}

Bruner (Bruner, 1990, in: Bar-Tal, 2007) defines the term "narrative" as a "construction that creates explicit links, building a sequence of historical and current events..." (ibid: 51). White (1974) expands this theme with the claim that "...historical narratives... are... verbal fictions... whose content is the fruit of invention..." (ibid: 306). In other words, one cannot refer to a national narrative as an absolute because cultural agents themselves are influenced by their own ideology which they use to process and present historical facts. Mediation between reported events is performed by linking them to various proto-generic narrative structures. As a result, even though they refer to the same facts, a different story is created in each culture (ibid.). Anderson (2000) also says that a nation is a modern imaginary invention that promises solidarity and support of elites. As mentioned earlier, the process of constructing a national narrative is bound in fiction or forgery (White, 1974; Smith, 2003). This phenomena is similar to the process of the creation of myth, which is not objective and does not present a given truth (White, 1974), just as a national culture is used as subjective text, told by each society to itself about itself in order to achieve current objectives (Gertz, 1973, in: Gordon, 2006). Renewal of the nation demands past myths for current and future objectives (Sela, 2007). They diverge significantly from a reliable version, they omit essential and significant details while emphasizing others and adding information to create a narrative sequence (Weinrib, 2002). Selective choice of facts and the creation of intentional forgetfulness are also important components in the design of the collective memory of a nation (Bloch, 1994; Hailan, 2004). Conversely, certain events are highlighted by Jewish and Arab societies. Now, the process of collective forgetfulness on the one hand and the emphasis placed on other events on the other hand create differences between various collective identities (Hailan, 2004). National narratives of Jewish society and Arab 
society are not merely different, but opposing (Bar-Tal, 2007; Sela, 2007). In the next section we will examine the way we see the "other" in Israel.

\section{Relating to the "other" in Israeli Society}

The term "other" indicates a different cultural group. Every human society has universal thought structures in its relationship towards the "other" (Fuoceau, 1986). Often, a person sees the "other" as a foreign, unknown character threatening his safety. Nadler (2000) writes that lack of knowledge of the "other" is the source of the problem. But, the "other" is not necessarily a stranger. Often the "other" is an integral part of society, but his otherness in fundamental areas is what defines him (Venezia, 2007). Oron (2006) sees the Arab "other" as the ultimate "other" in Israel. Gover (2000) claims that we need the "other", even an "other" that seems negative to us, in order to define our own identity. Lam (2000) thinks that an individual's intolerance toward a foreign culture testifies to his intolerance towards his own culture. Tadmor (2008) has reservations about the actual term "tolerance to the other" (ibid: 98) that highlights a lack of symmetry and balance between groups while demonstrating superiority of strength and arrogance. All this leads to the need for education to multiculturalism in Israel that will be discussed in the next section.

\section{Education to Multiculturalism in Israel}

The need for education to multiculturalism is a necessity in Israel's reality. The education system holds a central role in imparting social norms and cultural skills to the young generation. Therefore, aspirations for social change require changes in the objectives and content of curricula (Zamir, 2005; Sela, 2007). Two separate education systems exist in Israel for the Arab and Jewish societies, starting at kindergarten age, and there is distinct asymmetry between the two sectors in respect to knowledge of the "other" (Elhaj, 2003; Salomon, 2006). In view of that, the multi-cultural approach aspires to change the psychological aspect that is feeding the conflict. Some are convinced that a change from the bottom has the power to create wide-ranging change (Bar-Tal 2007; Bar-Shalom, 2004). Findings show that stereotypical conceptions of the "other" already exist in kindergarten age (Teichman, 2006). Therefore, education to multiculturalism is important even at a young age (Venezia, 2007). Cohen (1996) claims that a culture cannot be known unless its songs are sung and its dances danced, so exposure to the arts becomes an essential part of the process. In the next section we will expand on the role of the arts in instilling social norms at an early age.

\section{Role of Arts in Kindergarten Teaching}

Since early days, the influence of the arts on people had been widely known. The arts are included in teaching-bundles as part of the existing core curricula for kindergartens. They provide for the mental and physical needs of children and contribute to their overall normative development. For example, Yardeni-Yaffe (1981) ascribes importance to music in shaping personality by 
relieving stresses and pressures (ibid). Music and dance for the young child are creative vehicles for expression and communication using voice and body movement. This is thanks to universal musical thinking that enables the child to understand emotional-audio expressions of the other and even of a culture foreign to it. Moreover, music is a means for social expression and social cohesion in events and ceremonies (Inbar, 1996). Aristotle (Aristotle, 1977 in: Lorand, 1991) indicates the cognitive significance of the arts and their affect on shaping behavior and internal experiences. Yasoor and Kramer (2002) highlight the direct connection between the development of language and of thinking. Inbar (1996) defines music as "a distinctly cognitive-intellectual field that enables us to examine the complexity of our emotional world in a sophisticated and controlled way, using a highly abstract system of symbols (there: 1). Many people carry the banner of an integrative approach that combines arts with each other and with other knowledge fields, just as they are integrated and linked to each other in our daily life.

Some highlight the esthetic-humanistic value of art. Their approach believes in listening to music or reading literature only for the purpose of enjoyment and esthetic experience (Goldberg, 1995; Izhar, 1991). All the same, many see in children's literature a means to achieve moral and national goals. Through the arts it is possible to shape behavior patterns in children in a very efficient way, since the young child is not aware of their hidden messages (Plato, 1967 in: Lorand, 1991). Albercht (Albercht, 1956, in: Gonen, 1991) defines literature as a cultural indicator that strengthens common norms in society. Therefore, literature is used as a tool for national socialization of children and can be used as a faithful mirror of social changes (Zamir, 2005; Cohen, 1985). The next chapter presents a study unit for kindergarten where all activities arise from various works of art.

\section{Kindergarten Study-Unit: Development and Nurturing Awareness of the Existence of the Arab 'Other' and the Existence of the Jewish 'Other' by Means of the Arts at the Preschool Level}

The overall goal of the study-unit Development and nurturing awareness of the existence of the Arab 'other', and the existence of the Jewish 'other', by means of the arts at the preschool level is to provide the children with initial tools that enable a different conception of the "other", not based on common stereotypes and prejudice. Additional goals of the unit are:

- Children will become familiar with habits, traditions, holidays, dialects, personalities and characters of another culture.

- The children will form social contacts with their peers form the other sector and visit each other.

These are the unit's operative goals: 
1. Children from both sectors will dance and sing songs in Hebrew and Arabic.

2. The children will playact together stories about this initiative.

3. The children will demonstrate customs, ceremonies and celebrations from their own culture.

4. Children from both kindergartens will work in varied creation tables and play together in different parts of the kindergarten.

5. Before each meeting, the children will prepare a kindergarten monthly for the children from the other sector.

6. The children will work in a cultural centre with symbols that belong to the other culture.

The unit's content is organized in an integrative way that unifies issues from different disciplines. Literature and music are the fields of knowledge that provide mostly to the unit's content. Suggested working methods are: discussions in small groups, presentation of dialogue between characters in the books studied, interpretation of pictures, playacting a story, creating an orchestra, learning folk dances, exposing the children to characters and personalities of the other culture, familiarity with the musical instrument Oudh, various musical activities, songs, dances and recitations on the topic of JewishArab co-existence". Another way to develop awareness of the "other" that is included in the study unit is organizing meetings between Jewish and Arab children. Encouraging inter-cultural contacts is based on the "Contact Assumption" theory (Allport, 1954 in: Nadler, 2000) that believes in the personalization of the foreign group (Bar-Tal, 2007).

Thanks to the grant received from the Fund for Innovative Teaching, the educational initiative Development and nurturing awareness of the existence of the Arab 'other' and the existence of the Jewish 'other' by means of the arts at the preschool level was implemented in cooperation with Ms. Shatwa Zubeidat, principal of the Yasmim kindergarten from Bosmat Tivon. During the years 2011-2013 intercultural meetings were held between my kindergarten and the Bedouin kindergarten. In these meetings the children acted in Hebrew and in Arabic and were exposed to the other's narrative. For example, the Jewish children became familiar with the Koran and with Moslem holidays and customs. The Bedouin children were exposed to the Torah and to Jewish holidays. The children playacted Friday prayers as practiced in Islam and Friday night ritual as celebrated in a Jewish home. A joint pajama party was held for both kindergartens, and a Passover Seder was conducted in the Bedouin kindergarten. The children learned phrases in the other's language, planted together in the kindergarten's yard and playacted a story with each child speaking his own language. Prior to each meeting, the children prepared a kindergarten monthly which they gave to the children of the other kindergarten. The monthly included the children's experiences throughout the month. In each kindergarten, a culture centre was established where the children played with symbols belonging to the other culture.

In January 2013 this initiative was presented in the "Sede Trumot" 
conference held at Oranim College and won the Encouragement Award for Outstanding Initiative. This made it possible to hold joint meetings in the current school year, 2013-14, between my kindergarten and a Bedouin kindergarten from Rumat Haieb whose principal is Ms. Hadas Falah.

The current educational initiative was developed and evolved from the applied final project written as part of my graduate studies for the degree $\mathrm{M}$. Ed. at Oranim College under the guidance of Prof. Moshe Itzhaki. Thanks to this initiative, the children became familiar with a cultural group that was new to them and contacts were created between them. Parents from both kindergartens are supportive of the project and wonderfully cooperative.

\section{Summary}

In this article I presented the Kindergarten study-unit Development and nurturing awareness of the existence of the Arab 'other' and the existence of the Jewish 'other' by means of the arts at the preschool level. Seeing the kindergarten as a microcosm of society encourages me, as an educator in Israel aspiring to achieve social change, to expose the future generation to ideological aspects of other cultural groups that exist in our society. This led me, as part of my studies at Oranim College, to write this study unit with the goal of providing the children with the initial tools to enable a different conception of the "other", not based on existing societal stereotypes. The method I chose to achieve that is by using the arts and intercultural meetings between children in the two sectors.

The Fund for Innovative Teaching made it possible to implement this study unit. Thanks to its grant, this initiative is implemented in my kindergarten in Yoqne Am and in the Bedouin kindergartens in Bosmat Tivon and in Rumat Haieb. All the participating villages are not mixed, and thanks to this initiative the children are exposed to the "other" whom they would not have met otherwise. This is what makes this initiative unique.

In summary we can say that my educational initiative is one of many changes identified with the dynamic post-modern era, characterized as lack of uniformity, of continuity and of a single truth (Aviram, 2004). It reflects a reality where disciplines are linked to each other and enables students to see learning as life itself - not as a process of training for life - due to the close relationship between what is studied in the kindergarten and what exists outside it (Cohen, 1996). Darwin (Darwin, in: Venezia, 2006) found that the more plants growing next to each other are of different species, the better their chances to co-exist next to each other on the same field plot. It would be superfluous to spell out the link between Darwin's conclusion (ibid) and my educational initiative. 


\section{References}

Anderson, B. 2000. Segments from Patriotism and Racism; Commander, Map, Museum; Memory and Forgetfulness. In Imaginary Communities: Thought on the Sources of Nationalism and Its Spread. (pp 174-243). The Open University.

Aviram, R. 2004. Chapter 1: Why We Need a Futuristic School. In R. Aviram: The Futuristic School: A Research Journey into the Future of Education. (pp 29-66).

Bar-Shalom, Y. 2004. Ideal of Correction. Educational Initiatives in a Multi-cultural Society. Tel Aviv: Hidekel.

Bar-Tal, D. 2006. Socialization to Conflict: General View. In Y. Rahamim and D. Bar-Tal (Eds.) I Could Only Talk About the Conflict. Socialization for Conflict in Israeli-Jewish Society. Tel Aviv, Walter Libech for Education to Jewish-Arab coexistence.

Bar-Tal, D. 2007. Living with the Conflict. A Social-Psychological Analysis of Jewish Society in Israel. Jerusalem, Karmel Publishers.

Bloch, M. 1994. Following the Lie and Error. In M. Bloch. Apology for History. (pp 121-139). Jerusalem, the Bialik Institue.

Cohen, A. 1996. The Subject Method, Integration in Study Planning and Focussed Learning. In H. Cohen (Ed.) Applications in Focus. Jerusalem: Ministry of Education, Culture and Sport, Planning and Methods Department.

Cohen, A. 1985. Ugly Face in the Mirror: Reflection of the Jewish-Arab Conflict in Hebrew Children's Literature.Tel Aviv: Reshafim.

Elhaj, M. 2003. Education in the Shadow of the Conflict. Cultural Hegemony Against Controlled Multiculturalism. In M. Elhaj and A. Ben Eliezer (Eds.) In the Name of Security. Sociology of Peace and War in Israel in a Changing Era. (pp 295327). Haifa University Publishers, Pardes Publishers.

Foucault, M. 1986. A History of Insanity in the Age of Reason. Jerusalem: Keter.

Goldberg, L. 1955. Between a Children's Author and his Readers. Sifriyat Poalim.

Gonen, R. 1991. Value Messages in Israeli Illustrated Children's Books for Early Childhood in the Years 1948-1984. Haifa, HMOL.

Gordon, D. 2006. Introduction. In D. Gordon (Ed.). Study Subjects Under Examination: Alternatives to Conventional Teaching in Schools. (pp 9-23). Jerusalem, Van Leer and Hakibbutz Hameuhad.

Gover, N. 2000. Critical Pedagogy and Education for Multiculturalism as a Conscious Paradoxical Position. In M. Bar Lev (Ed). Education for Culture in a Multicultural Society. Issues in Teachers' Training, (pp 51-70). Jerusalem, The Hebrew University In Jerusalem and the Ministry of Education.

Hailan, N. 2004. History in a Box: Television News and Collective Memory. In H. Breshit, M. Zimerman and S. Zand (Eds.). Cinema and Memory. Dangerous Liaisons? (pp 13-32). Jerusalem, Zalman Shazar Centre for Israeli History.

Inbar, A. 1996. Core Program in Music Education - Invitation to Discussion. Key: Periodical for Music Teachers. In Education.gob.il

Izhar, S. 1991. Stop Teaching Literature. In S. Izhar Two Polemics, (pp 119-168), Tel Aviv: Am Oved.

Lam, Z. 2000. Multi Cultural, Inter Cultural Education - is it Real? In M. Barlev (Ed.) Education for Culture in a Multi Cultural Society, Teachers' Training Department at the School for Education. Jerusalem: The Hebrew University.

Lorend, R. 1991. On the Nature of Art. Tel Aviv: Dvir. 
Nadler, A. 2000. Inter-Group Conflict and its Development: Perspective of Social Psychology. In R. Halabi (Ed.) Dialogue Between Identities: Meetings of Arabs and Jews in Neveh Shalom. (pp 28-46). Tel Aviv: Hakibbutz Hameuhad.

Oron, Y. 1996. Relation to the "Other" in Jewish-Israeli Society. Hakhinukh Usevivo, 18. (pp 9-15).

Sela, R. 2007. Six Days and Another Forty Years. Petah Tikva Museum of Art.

Smith, D. 2003. Sections from Social Structuring and Ethnic Genealogy. In The Nation in History. (pp 72-100). Jerusalem: Israeli Historical Society.

Tadmor, I. 2008. Mixed Education. A Collection of Notes. Self Published.

Teichman, Y. 2006. Socialization of Children in Conflict. In Y. Rahamim and D. BarTal (Eds.) I Could Only Talk About the Conflict. Socialization for Conflict in Israeli-Jewish Society. Tel Aviv, Walter Libech for Education to Jewish-Arab Coexistence.

Totri, M. 2009. The Jews and Their History. The Arabs and the History of the Other. Presented in conference Writing of History and Teaching it in a MultiDisciplinary Vision. Haifa: University of Haifa.

Venezia, N. 2007. Maze of Mirrors: About Education for Multiculturalism in Israel. Haifa, Pardes.

Weinrib, A. 2002. History - Myth or Reality? In A. Weinrib, History - Myth or Reality? - Thoughts on the State of the Profession. (pp 218-251). Tel Aviv, The Open University.

White, H. 1974. Historical Text as Literary Product. In A. Weinrib, 1985 (Ed.) Historical Thinking. Volume II. (pp 305-322). Tel Aviv, The Open University.

Yardeni-Yaffe, T. 1981. Expression and Creativity in Music as Therapy: Collection of Therapy Experiences with Organically or Emotionally Defective Children and the Fruit of Personal Experience in Therapy Using Sound, Colour and Movement. Tel Aviv: Hakibbutz Hameuhad.

Yasoor, H. and Kramer, A. 1991. Discovering the Creative Act. Literature in Elementary School. Kiryat Bialok: "Akh".

Yona, I. 2007. Multi Cultural Education in Israel: Challenge and Difficulties. In P. Perry (Ed.) Education in a Multi Cultural Society. Pluralism and Meeting Points Between Cultural Chasms. (pp 39-66). Jerusalem, Karmel Publishers.

Zamir, S. 2005. New Times, Old Books. Faces, 31. (pp 53-61). 
